\title{
Dental radiographic procedures during COVID-19 outbreak and normalization period: recommendations on infection control
}

\author{
Betul Ilhan ${ }^{1}$ (D) I Ibrahim Sevki Bayrakdar ${ }^{2} \cdot$ Kaan Orhan $^{3}$
}

Received: 27 May 2020 / Accepted: 18 June 2020 / Published online: 29 June 2020

(c) Japanese Society for Oral and Maxillofacial Radiology and Springer Nature Singapore Pte Ltd. 2020

\begin{abstract}
Dental professionals have always been meticulous about infection control due to high risk of cross-contamination during dental procedures. Nevertheless, there is an urgent need to review and revise our current practice of infection control and develop more strict protocols that will prevent nosocomial spread of infection during COVID-19 outbreak and future pandemics. The risk of contamination is high during dental radiography if proper disinfection techniques are not applied. This document provides advice and guidance for infection control when practicing dental radiography during COVID-19 pandemic.
\end{abstract}

Keywords Dental radiology · COVID-19 · Infection control

\section{Introduction}

The new coronavirus disease (COVID-19) caused by the recently recognized SARS-CoV 2 virus is having devastating impacts on all aspects of life including economy, social life and health care [1,2]. On the other hand, health care facilities are required to provide continuous service, treatment and relief for those in need and are rarely closed during any crises [3]. The primary route for transmission of virus is through droplets and aerosols and therefore dental health care workers are among the medical professionals who are at extreme risk of getting infected and further spreading the virus [4-7]. The long and unpredictable incubation period (up to 27 days) [1] of the virus and the high rates of asymptomatic carriers (80\%) [4] further challenges infection control measures during dental practice. There is no available universal guideline regulating the dental care provision during any epidemic or pandemic. However, dental pain is the most commonly encountered health problem among any

Betul Ilhan

ilhanbetul@yahoo.com

1 Department of Oral and Maxillofacial Radiology, Faculty of Dentistry, Ege University, Izmir, Turkey

2 Department of Oral and Maxillofacial Radiology, Faculty of Dentistry, Eskisehir Osmangazi University, Eskisehir, Turkey

3 Department of Oral and Maxillofacial Radiology, Faculty of Dentistry, Ankara University, Ankara, Turkey given population and requires immediate care or treatment [8]. This is proven by the fact that the demand for urgent dental treatment decreased by only $38 \%$ since the beginning of pandemic in China [9]. It is evident that patients applying for dental emergency treatment will likely require dental imaging.

So far, several reports and articles that focuses on screening, clinical features, patient management during surgical or endodontic procedures have been published [6, 7, 10-12]. Postponing all elective dental treatments and providing care for only emergency cases during the pandemic are recommended [6, 7, 10-12]. There are limited number of reports on dental radiography during COVID-19 [13-15], which is a critical component of diagnostic work-up and involves significant potential for cross-contamination through exposure to saliva and/or blood. The presence of SARS-CoV 2 virus has been revealed in both blood and saliva samples [5] of COVID-19 patients, which necessitates reviewing our current practice of infection control during dental radiography to develop more strict protocols that will prevent nosocomial spread COVID-19. So far, Centre for Disease Control (CDC) Guidelines published in 2003 has been followed in dental radiology clinics [16].

Provided that intraoral radiographs may stimulate gag reflexes, coughing and saliva secretion, it is recommended to prefer extraoral imaging techniques such as panoramic radiography and cone-beam computed tomography (CBCT) during the outbreak $[6,7,12]$. Although panoramic radiography can substitute for intraoral radiographs during these difficult 
times, CBCT is associated with much higher radiation doses and should not be used as an alternative to intraoral imaging [13]. Additionally, there may be cases where dental practitioners require better radiographic image quality for a particular tooth (e.g. traumatized upper anterior incisor) or access to extraoral imaging techniques may not always be available, especially in low- and middle-income countries. In such, conditions intraoral imaging may be mandatory for dental practitioners. This document provides advice and guidance for infection control when practicing dental radiography during COVID-19 pandemic. The recommendations are based on previous reports [17-22] and available data on SARS-CoV 2 [23-25].

\section{Infection control for environmental surfaces}

Environmental surfaces in dental radiology clinics include furniture and other fixed items inside and outside of examination rooms (e.g. tables, floors and walls, chairs, light switches). These surfaces are more likely to be contaminated and must be properly cleaned and disinfected. It should be kept in mind that SARS-CoV 2 virus can persist on inanimate surfaces for $4 \mathrm{~h}$ up to 7 days depending on the temperature, humidity, type of surface and virus load [24].

- World Health Organization (WHO) suggests that outpatient/ambulatory care rooms, particularly high-touch surfaces such as light switches, door handles, trays, sinks, tables, water/beverage pitchers, and floors should be cleaned and disinfected after each patient in visit, and low-touch surfaces should be cleaned daily. At least one terminal clean every day is recommended [23, 25].

- Hypochlorite $(0.5 \%$ for blood and body fluids, $0.1 \%$ for environmental disinfection), 70-90\% ethanol and $>0.5 \%$ hydrogen peroxide can be used for disinfection [23, 25]. A minimum of 1-min contact time with the disinfectant solution is advised.

- Some disinfectants can be inactivated in the presence of organic material; therefore, the surfaces (especially hightouch surfaces, in case of blood, saliva or other bodily fluids) should be thoroughly cleaned with soap/detergent or water using mechanical action (scrubbing) prior to the use of disinfectants [23, 25].

- Cleaning equipment should be well maintained and the buckets containing detergent and/or disinfectant solutions must be discarded after each use in areas with suspected/ confirmed patients with COVID-19. Fresh solutions must be prepared on a daily basis or for each cleaning shift [23, 25].

- Spraying or fogging of certain chemicals (e.g. formaldehyde, chlorine-based agents) is not recommended for COVID-19. Adjunct technologies using UV irradiation supplement but do not replace the need for manual cleaning procedures [23].

- Frequent ventilation of the examination rooms and cleaning of the air filters should be ensured.

\section{Infection control for staff and patients}

During the previous SARS (SARS-CoV) outbreak, Seto et al. [26] reported that proper use of standard precautions is adequate to prevent the nosocomial spread of the disease in the absence of aerosol-producing procedures. Nevertheless, all patients must have surgical masks and coughing/ sneezing manners should be briefly reminded to the patient prior to acceptance to the examination room.

- The minimal personal protective equipment (PPE) for dental radiology staff should include disposable surgical mask, cap, gloves, long-sleeved gown and goggles/ face shield. Goggles/face shields must be cleaned and disinfected with soap/detergent, water and at least $70 \%$ alcohol-based disinfectants [27].

- The staff must be trained on the procedure for dressing and undressing [27]. Proper hand hygiene must be maintained before and after use of PPE.

- Nail polish, rings and accessories are prohibited for all health care professionals and it is recognized that beards decrease FFP2 mask (used for aerosol producing procedures) efficacy [27].

- For medical radiologists, it is recommended that the staff in direct contact with the patient and present in the department should be reduced and shift work should be applied. The same regulations should be considered for dental radiology department as well [28].

- The appointments must be spaced out (30 min) to leave adequate time for disinfection of equipment.

\section{Infection control for dental radiography: general considerations}

Previous research indicated that microorganisms can remain viable on radiographic equipment for up to $48 \mathrm{~h}$ and as long as 2 weeks in X-ray developer/fixer [21]. If proper disinfection techniques is not applied when taking any dental radiograph, the potential for cross-contamination of radiographic equipment with blood and/or saliva would be significantly high $[17,18,21]$.

Most reusable items used in dental radiology are considered semi-critical (contact with mucous membrane) or noncritical (contact with intact skin). Reusable semi-critic items such as bite guides, film positioning devices must be sterilized with high-level disinfectants after each use or covered 
with plastic sheets, wraps or pieces with adhesive edges, if sterilization or barrier-protection is not possible, then disposable items should be used [17, 18, 21]. Non-critical items such as chin rest, hand grasps can be barrier-protected and the covers must be changed after each patient. Surface barriers provide adequate protection while eliminating the need for clean and disinfect surfaces between patients [17]. Lead-apron and thyroid collars should be disinfected with a low-level disinfectant (e.g. quaternary ammonium compounds) and should be suspended on a coat hanger after each use. Attention should be paid to minimize the positioning and exposure errors during radiographic examination in order to eliminate the need for repeated exposures which may additionally increase the risk of contamination. The working station (computers, screens, scanners etc.) should be kept remote from the patient examination rooms and the operator in charge of exposures should have limited access to the working station or to the dark room. The radiologists should have a separate room to interpret images and prepare the reports. On the basis of experience with SARS, the use of a remote satellite radiography center or utilization of mobile radiographic equipment are also recommended for patients with known COVID-19 disease [28].

Oral rinse with $1 \%$ hydrogen peroxide or $0.2 \%$ povidone solution prior to any dental procedure has been shown to reduce viral load [29]. Considering the close contact of mucous membranes during panoramic, $\mathrm{CBCT}$ and intraoral examination, we recommend oral rinsing for the patients before using these techniques.

\section{Panoramic radiography}

- The panoramic radiography room must be prepared, the machine should be turned on and the rotating component should be returned to the start point before the patient is accepted. If conventional films or storage phosphor sensors are used, the cassette should be placed before accepting the patient $[17,18]$.

- Non-critical surfaces and items during panoramic radiography includes chin rest, handgrips, head-positioning devices/head stabilizers, remote switch, control panel (chairs if patients need to be seated). All non-critical items should be barrier-protected with plastic sheets or wraps, and should be changed after each patient. Noncritical items can be disinfected with intermediate level disinfectants (70\% ethyl alcohol, 70\% isopropyl alcohol) daily and when contaminated. The bite-guide (semi-critical item) must either be covered with a disposable sheath or sterilized following patient use. If both options are not possible, then disposable bite-guides must be employed $[17,18,21]$.

- In order to minimize the spent time in the examination room, registration of the patients should take place out- side and the patient must remove all metal accessories and dentures before entering the room [17, 18, 21].

- In case of physical contact with the patient during positioning, the gloves must be changed before taking the cassette out after exposure (for conventional films and storage phosphor plates).

- The cassettes should be held with clean gloves during transfer to the work station or dark room.

\section{CBCT imaging}

Same infection control measures also apply for CBCT. The only difference is the type of non-critical items on the device.

- Non-critical items on CBCT devices include remote switch, control panel, chin rest, handgrips, head stabilizers, patient table (supine positioning) and patient chair (seated positioning). All non-critical items should be barrier-protected as described above and disposable bite guides must be used if barrier-protection or sterilization is not possible.

\section{USG imaging}

Swellings and pain in masticatory muscles may also require ultrasound (US) imaging during COVID-19 pandemic. Transducers may carry pathogens, including viruses such as human papillomavirus (HPV), unless properly disinfected between examination sessions. The infection prevention and control recommendations of Ultrasound Working Group of the European Society of Radiology should also be followed for COVID-19 [30]. High level of disinfection should be applied for ultrasound transducers. The transducers must be used with protective covers such as medical gloves, or condoms during contact with mucous membranes or any body fluids (including interventional procedures, injections, tissue sampling, use in the theater, etc.). Sterile gel should be used inside and outside covers. The following specific measures are recommended by American Institute of Ultrasound in Medicine (AIUM) for COVID-19 [31].

1. Cleaning-Cleaning involves all ancillary equipment involved in the procedure at hand. A cover sheet may be used as a physical barrier between the keyboard/console and the operator, in addition to low level disinfectant cleaning. If possible, a dedicated system (scanner and transducers) for COVID-19 positive or suspected patients should be used. Transducers should be cleaned after each examination with soap/water and low level disinfectant (quaternary ammonium) sprays or wipes.

2. Disinfection-As stated above, all internal transducers (e.g., intraoral, transesophageal) as well as intraopera- 
tive transducers require high level disinfection before they can be used on another patient. For disinfection, an antiseptic agent-impregnated towel (such as glutaraldehyde, peracetic acid, ortho-phthalaldehyde, hypochlorite/hypochlorous acid, phenol/phenolate) as well as a type C ultraviolet light can be used [30, 31].

\section{Intraoral radiography}

During intraoral radiography transmission of the disease is possible through either direct contact with saliva or crosscontamination. Cross-contamination may also occur when the clinician handles the digital sensors or opens film packets [17-21].

- Use of autoclavable or disposable film/receptor holders is recommended to decrease clinician's contact with saliva while placing the film/receptor [17].

- The high-touch and non-critical items such as tube head, $\mathrm{X}$-ray cone, control panel, exposure button, head rest and adjustment control, chair and adjustment control and countertop/working area should be barrier-protected (plastic sheets, wraps) and the barriers should be changed after each patient. Intermediate level disinfectants $(70 \%$ ethyl alcohol, 70\% isopropyl alcohol) can be used for disinfection of these items on a daily basis or when contaminated [17, 18, 21].

- Paper towels should be kept ready over the counter in order to remove excess saliva after exposure.

- Film/receptor holders (packed and sterilized) and film/ storage phosphor plates should be dispensed aseptically in a disposable container.

- Plastic sheaths must be used for all kind of intraoral films/receptors and the integrity of sealed barrier must be verified before placement. The use of double barriers for films and plates and latex finger cots in conjunction with a plastic sheath for direct digital sensors will more effectively prevent cross-contamination [32, 33].

- If charged-coupled-device (CCD) sensors are used the cord must be wrapped with a plastic cover before placement and the cover must be changed after each patient [17].

- Following exposure, the plastic sheaths should be immersed in disinfectant solution and left to air dry. The sheaths must be opened carefully, hand contact with the film/receptor and contact with saliva must be avoided. While opening the protective cover, the films and phosphor plates should be allowed to drop out in a clean disposable cup and the cup must be held with clean gloves. Then, the film/plate can then be transferred to work station or dark room $[17,32,33]$.

- Since digital receptors cannot be sterilized by conventional means. Manufacturers' recommendations should be followed. For digital sensors (CCD and plates) wiping with intermediate level disinfectants after each use (70\% ethyl alcohol, 70\% isopropyl alcohol) is recommended. Phosphor plates may also be gas sterilized with ethylene oxide [17, 32, 33].

- For conventional films, the operator in dark room must remove the film from the vinyl package without touching the film. The lead foil, black paper and the package should be discarded and film should be allowed to drop out on a clean disposable cup before manual/automated processing [17].

- Second hard copies of radiographic images should be avoided and teleradiology systems should be preferred to prevent contamination [14].

A majority of these infection control procedures have been already known as inseparable parts of everyday dental radiology practice, however, the new COVID-19 disease has dramatically altered our habits and the way we live our lives due to high transmission rate. More serious implementation and control of current infection control regulations is absolutely required to manage the disease and prevent the global spread of the virus. It is obvious that this pandemic will inevitably trigger a new era in dental profession both during normalization period and afterwards. Therefore, the present guide has been awarded for infection control when practicing dental radiography during this pandemic. These recommendations which are based on the previous reports and current data on the disease can be also be applied during possible future outbreaks.

\section{Compliance with ethical standards}

Conflicts of interest Betul Ilhan received no financial support and declare no potential conflicts of interest. Ibrahim Sevki Bayrakdar received no financial support and declare no potential conflicts of interest. Kaan Orhan received no financial support and declare no potential conflicts of interest. This article does not contain any studies with human or animal subjects performed by the any of the authors.

\section{References}

1. Gralinski LE, Menachery VD. Return of the coronavirus: 2019nCoV. Viruses. 2020;12:135.

2. World Health Organisation (WHO) 2020. Virtual press conference on COVID-19. https://www.who.int/westernpacific/news/ speeches/detail/virtual-press-conference-on-covid-19-outbreakin-the-western-pacific-region-21-april-2020. Accessed 30 Mar 2020

3. Ahmed MA, Jouhar R, Ahmed N, et al. Fear and practice modifications among dentists to combat novel coronavirus disease (COVID-19) outbreak. Int J Environ Res Public Health. 2020;17:E2821 
4. Lai CC, Shih TP, Ko WC, Tang HJ, Hsueh PR. Severe acute respiratory syndrome coronavirus 2 (SARS-CoV-2) and coronavirus disease-2019 (COVID-19): the epidemic and the challenges. Int J Antimicrob Agents. 2020;55:105924.

5. To KK, Tsang OT, Chik-Yan Yip C, et al. Consistent detection of 2019 novel coronavirus in saliva. Clin Infect Dis. 2020. https:// doi.org/10.1093/cid/ciaa149.

6. Meng L, Hua F, Bian Z. Coronavirus disease 2019 (COVID-19): emerging and future challenges for dental and oral medicine. $\mathrm{J}$ Dent Res. 2020;99:481-7.

7. Fallahi HR, Keyhan SO, Zandian D, Kim SG, Cheshmi B. Being a front-line dentist during the Covid-19 pandemic: a literature review. Maxillofac Plast Reconstr Surg. 2020;42:12.

8. Cavalheiro $\mathrm{CH}$, Abegg $\mathrm{C}$, Fontanive VN, Davoglio RS. Dental pain, use of dental services and oral healthrelated quality of life in southern Brazil. Braz Oral Res. 2016;30(1):S1806-83242016000100272.

9. Guo H, Zhou Y, Liu X, Tan J. The impact of the COVID-19 epidemic on the utilization of emergency dental services. J Dent Sci. 2020. https://doi.org/10.1016/j.jds.2020.02.002.

10. Ather A, Patel B, Ruparel NB, Diogenes A, Hargreaves KM. Coronavirus disease 19 (COVID-19): implications for clinical dental care. J Endod. 2020;46:584-95.

11. Abramovitz I, Palmon A, Levy D, et al. Dental care during the coronavirus disease 2019 (COVID-19) outbreak: operatory considerations and clinical aspects. Quintessence Int. 2020;51:418-29.

12. American Dental Association. ADA recommending dentists postpone elective procedures. 16 March 2020. https://www.ada.org/en/ press-room/news-releases/2020-archives/march/ada-calls-upondentists-to-postpone-elective-procedures. Accessed 17 May 2020.

13. Dave M, Coulthard P, Patel N, Seoudi N, Horner K. Use of dental radiography in the COVID-19 pandemic. J Dent Res. 2020. https ://doi.org/10.1177/0022034520923323.

14. Saki M, Haseli S, Iranpour P. Oral radiology center as a potential source of COVID-19 transmission; points to consider. Acad Radiol. 2020. https://doi.org/10.1016/j.acra.2020.04.040.

15. Recommendations for Diagnostic Imaging during COVID-19 pandemic. 2020, www.rcseng.ac.uk/dental-faculties/fds/coronavirus/.

16. National Center for Chronic Disease Prevention and Health Promotion (CDC). Guidelines for Infection control in dental healthcare settings. 2003; December 19/52(RR17):1-61.

17. Infection control practices in dental radiology. In: SM Mallya, $\mathrm{W}$ Ernest, N Lam, editors. White and Pharoah's oral radiology principles and interpretation 8th ed. Elsevier Publications, p. 798-802.

18. Bartoloni JA, Chariton DG, Flint DJ. Gen Dent. 2003;51:264-71.

19. Hubar JS, Gardiner DM. Infection control procedures used in conjunction with computed dental radiography. Int J Comput Dent. 2000;3:259-67.

20. MacDonald DS, Waterfield JD. Infection control in digital intraoral radiography: evaluation of microbiological contamination of photostimulable phosphor plates in barrier envelopes. $\mathbf{J}$ Can Dent Assoc. 2011;77:b93.

21. Palenik CJ. Infection control practices for dental radiography. Dent Today. 2004;23:52-5.
22. Bali RK, Chaudhry K. Maxillofacial surgery and COVID-19, The Pandemic !! J Maxillofac Oral Surg. 2020;19(2):159-61.

23. World Health Organization (WHO). Cleaning and disinfection of environmental surfaces in the context of COVID-19. Interim guidance 15 May 2020. https://www.who.int/publications-detail/ cleaning-and-disinfection-of-environmental-surfaces-inthe-conte xt-of-covid-19.

24. Revel MP, Parkar AP, Prosch H, Silva M, Sverzellati N, Gleeson F, et al. COVID-19 Patients and the Radiology Department-Advice From the European Society of Radiology (ESR) and the European Society of Thoracic Imaging (ESTI). Eur Radiol. 2020. https://doi. org/10.1007/s00330-020-06865-y.

25. Occupational Safety and Health Act. OSHA 3990-03 2020. Guidance on Preparing Workplaces for COVID-19. https://www.osha. gov/Publications/OSHA3990.pdf24.

26. Seto WH, Tsang D, Yung RW, Ching TY, Ng TK, Ho M, et al. Effectiveness of precautions against droplets and contact in prevention of nosocomial transmission of severe acute respiratory syndrome (SARS). Lancet. 2003;361:1519-20.

27. European Centre for Disease Prevention and Control. Guidance for wearing and removing personal protective equipment in healthcare settings for the care of patients with suspected or confirmed COVID-19; 2020. https://www.ecdc.europa.eu/sites/default/. Accessed 23 Mar 2020.

28. Kooraki S, Hosseiny M, Myers L, Gholamrezanezhad A. Coronavirus (COVID-19) outbreak: what the department of radiology should know. J Am Coll Radiol. 2020;17:447-51.

29. Peng X, Xu X, Li Y, Cheng L, Zhou X, Ren B. Transmission routes of 2019-nCoV and controls in dental practice. Int J Oral Sci. 2020;12(1):1-6.

30. Nyhsen CM, Humphreys H, Koerner RJ, Grenier N, Brady A, Sidhu $\mathrm{P}$, et al. Infection prevention and control in ultrasoundbest practice recommendations from the European Society of Radiology Ultrasound Working Group. Insights Imaging. 2017;8:523-35.

31. Guidelines for cleaning and preparing external- and internal-use ultrasound transducers between patients, safe handling, and use of ultrasound coupling gel. American Instutite of Ultrasound in Medicine Offical Statement, May 2020. https://www.aium.org/ accreditation/Guidelines_Cleaning_Preparing.pdf.

32. Choi JW. Perforation rate of intraoral barriers for direct digital radiography. Dentomaxillofac Radiol. 2015;44:20140245.

33. Hokett SD, Honey JR, Ruiz F, Baisden MK, Hoen MM. Assessing the effectiveness of direct digital radiography barrier sheaths and finger cots. J Am Dent Assoc. 2000;131:463-7.

Publisher's Note Springer Nature remains neutral with regard to jurisdictional claims in published maps and institutional affiliations. 